\title{
MODELLING AND SIMULATION OF VEHICLE SPEED GUIDANCE IN CONNECTED VEHICLE ENVIRONMENT
}

\author{
Wu, W. ; Li, P. K. ${ }^{* *} \&$ Zhang, Y.**\# \\ * School of Traffic and Transportation Engineering, Changsha University of Science and Technology, \\ Changsha 410076, China \\ ${ }^{* *}$ Shenzhen Urban Transport Planning Center CO. LTD, Shenzhen 518021, China \\ ${ }^{* * *}$ School of Naval Architecture, Ocean and Civil Engineering, Shanghai Jiao Tong University, \\ Shanghai 200240, China \\ E-Mail:weilliamwu@gmail.com, lipengkai1990@163.com, \\ darrenzhy@sjtu.edu.cn ( ${ }^{\#}$ Corresponding author)
}

\begin{abstract}
Most previous works on urban traffic efficiency focused on the optimization of signal timings, assuming vehicle speed was fixed or followed a giving distribution. In this paper, based on the two way communication between vehicles and signal controller in Connected Vehicle (CV) environment, we developed two vehicle speed guidance methods to decrease delay and number of stops at intersections. By using Visual Basic and VISSIM COM interface, the simulation model consists of three modules: the signal timing, the vehicle speed guidance, and the dynamic optimization. A field intersection of Cao'an Road and Lvyuan Road in Shanghai is employed for simulation tests. Compared with the simulation results optimized by classical signal control method, the proposed methods can significantly decrease delays and number of stops, and improve the efficiency of traffic control.
\end{abstract}

(Received, processed and accepted by the Chinese Representative Office.)

Key Words: Traffic Simulation, Speed Guidance, Connected Vehicle, Signalized Intersections

\section{INTRODUCTION}

As a result of rapid urbanization and motorization in China in the past 2 decades $[1,2]$ traffic congestion has become a severe issue and even a major cause of urban traffic and environment problems [3, 4]. An increasing number of researchers have recognized that decreasing delay and number of stops at signalized intersections is a potentially effective strategy for relieving traffic congestion. In practice, there is also an increasing emphasis on efficient traffic signal operations and strategies in many big cities within developing countries, such as Beijing, Shanghai, and Jinan in China. Compared with the considerable amount of time and resources to build urban expressway, inexpensive solutions that do not involve new infrastructure investment are more desirable [5-7].

Traffic signal optimization is one of these promising low-cost options. Since Webster proposed the original signal timing method, which resulted in a significant reduction of vehicle delays [8], many studies have proposed signal timing strategies and documented the benefits of signal timing program implementations. Most of the literature falls into the following two classes: mathematical programming approach and simulation-based approach [9]. Mathematical programming approach employed a set of mixed integer linear programming (MILP) formulations to minimize the total intersection delays or to maximize the green bandwidth [10-12], while simulation-based approach are developed to represent the complicated interactions between traffic flow interactions and signal timing parameters [1315].

Most previous studies, including isolated intersection signal timing methods $[16,17]$ and coordinated signal timing methods [18, 19], focus on optimizing signal timings without considering speed. Even with a small traffic demand, real-time travel speed is a function of 
several factors, including driver behaviour, vehicle characteristics, and the impacts of upstream signals and traffic conditions. A departure from the constant speed values used in these algorithms may result in low traffic control efficiency, or even traffic signal timing system failure. Vehicle speed determines the time required for a vehicle traveling from an upstream intersection (and vehicle detector) to a downstream intersection. This duration is a critical component of signal timing strategy optimization algorithms. Therefore, different vehicle travel speeds require different signal timing programs, even under similar traffic conditions.

Although speed is very important to both the efficiency and safety of signal timing systems [20], and the benefits of integrating speed into signal timing programs are known [21, $22]$, technical difficulties remain in reliably detecting and communicating travel speed in real time between vehicles and traffic controllers. Recently, the development of vehicular communication systems, called Connected Vehicle (CV) systems, where vehicles are equipped with $5.9 \mathrm{GHz}$ Dedicated Short Range Communications (DSRC) with communication distance 500 1000 meters [23-25] or other wireless communications technologies provide an interesting platform for deployment. These systems will enable vehicles to send and receive messages to and from other vehicles (V2V) and the infrastructure (V2I) [26, 27]. This communications capability could be used to send messages to vehicles based on local geometric considerations as well as actual traffic situations when a vehicle approaches an intersection.

Based on the significantly progresses of Connected Vehicle (CV) systems, the way to design signal timing systems are now changed. While traditional video and in-pavement detectors can generally provide information about presence [28], CV technologies allow signal controller to guide vehicle travel speed according to current traffic conditions and signal timing states. That makes it feasible to vary vehicle speed based on the needs of signal timing strategies.

This research focuses on developing a travel speed guidance method to decrease delay and number of stops for isolated intersections. The primary goals of this paper are to: 1) explicitly capture the dynamic interaction between vehicle speeds and signal timings; 2) build a simulation model to optimize signal timings and recommend bus speed in a united framework, and 3) improve traffic efficiency based on speed guidance and minimize travel delays.

\section{DEVELOPMENT OF OPTIMIZATION AND SIMULATION APPROACH}

\subsection{General notation and terminology}

The notations used hereafter are summarized in Table I.

\subsection{Problem description}

As shown in Fig. 1, if the first vehicle travels normally, it will arrive at the intersection at time $T_{a}$ and be stopped by a red light. If we do not want this vehicle to stop, the common practice is to extend or hold the green light $\left(T_{a}-T_{r}\right)$ seconds for the vehicle, then it will arrive at the intersection during green. However, extending the green light causes traffic flow at the conflicting approach experience some extra delays that limit its applicability. In Connected Vehicle environment, based on two way communication between signal controller and vehicle, speed guidance is another better solution in order to make the vehicle clear the intersection without stopping. By guiding the vehicle accelerate from $V_{0}$ to $V_{1}$, the vehicle can also arrive at the intersection during green without adjusting traffic lights duration. 
Table I: Key variables (notations) used in the formulations.

\begin{tabular}{|c|c|l|}
\hline No. & $\begin{array}{c}\text { Key } \\
\text { variables }\end{array}$ & \multicolumn{1}{c|}{ Description } \\
\hline 1. & $a$ & Accelerated speed for vehicles $\left(\mathrm{m} / \mathrm{s}^{2}\right)$ \\
\hline 2. & $g_{e}$ & Effective green time duration for a phase (s) \\
\hline 3. & $L_{i}$ & Distance from vehicle $i$ to stop line $(\mathrm{m})$ \\
\hline 4. & $l$ & Number of lanes of a phase $(\#)$. \\
\hline 5. & $N$ & Number of vehicles clear the intersection $(\# . v e h)$ \\
\hline 6. & $S$ & Saturation volume for a single lane $(\# . v e h / h)$ \\
\hline 7. & $T_{a}$ & Time instant of a vehicle arrives at the stop line $(\mathrm{s})$ \\
\hline 8. & $T_{d}$ & Time instant of queue dissipated $(\mathrm{s})$ \\
\hline 9. & $T_{g}$ & Time instant of green light begins $(\mathrm{s})$ \\
\hline 10. & $T_{g}{ }^{e}$ & Time instant of green light ends $(\mathrm{s})$ \\
\hline 11. & $T_{0}$ & The current time (s) \\
\hline 12. & $t_{g}$ & Time duration of green light $(\mathrm{s})$ \\
\hline 13. & $T_{i}$ & Time duration for a vehicle travel from the current position to stop line $(\mathrm{s})$ \\
\hline 14. & $t_{s}$ & The minimal time headway for vehicles $(\mathrm{s})$ \\
\hline 15. & $V_{i 0}$ & Initial travel speed of vehicle $i(\mathrm{~m} / \mathrm{s})$ \\
\hline 16. & $V_{i}$ & The objective speed for vehicle $i$ after speed guidance $(\mathrm{m} / \mathrm{s})$ \\
\hline 17. & $V_{\max }$ & The maximum bus speed limit $(\mathrm{m} / \mathrm{s})$ \\
\hline 18. & $V_{\min }$ & The minimum bus speed limit $(\mathrm{m} / \mathrm{s})$ \\
\hline
\end{tabular}

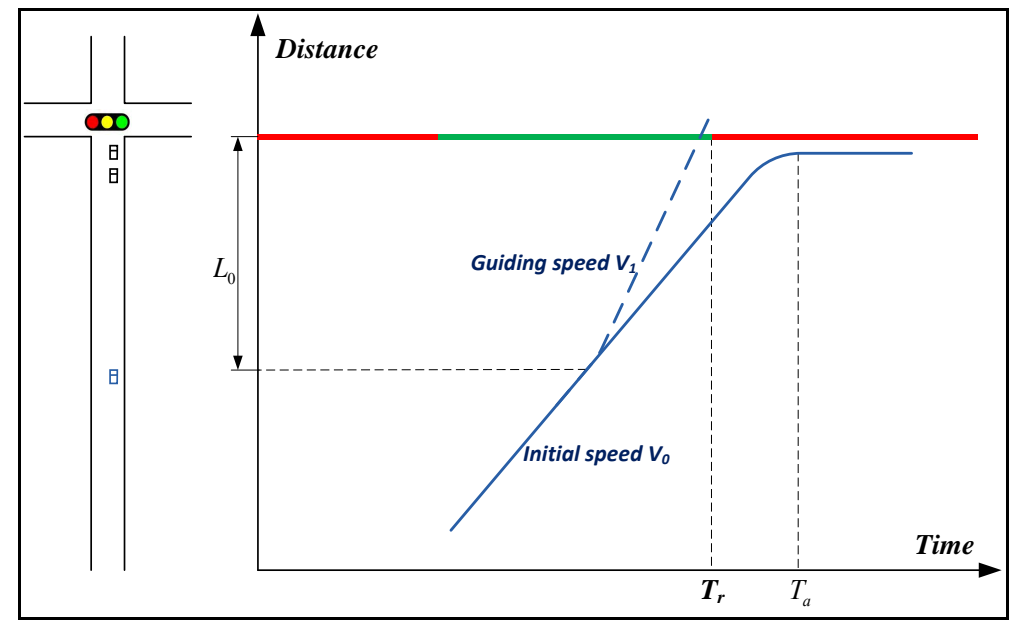

Figure 1: Speed guidance before the vehicle arrives at the intersection.

\subsection{The difference between "single-vehicle speed guidance method" and "multi-vehicles cooperated speed guidance method"}

In single-vehicle speed guidance method, according to the status of the traffic light, vehicles are treated individually without regard to the surrounding vehicles. If vehicles travel normally and can clear the intersection without stopping, then speed guidance is not required.

In multi-vehicles cooperated speed guidance method, vehicles in the same approach are considered together. Based on the speed guidance, vehicles not only make themselves travel through the intersection uninterrupted, but they need to help other vehicles to clear the intersection.

The difference between "single-vehicle speed guidance method" and "multi-vehicles cooperated speed guidance method" can be illustrated in Figs. 2 and 3. 


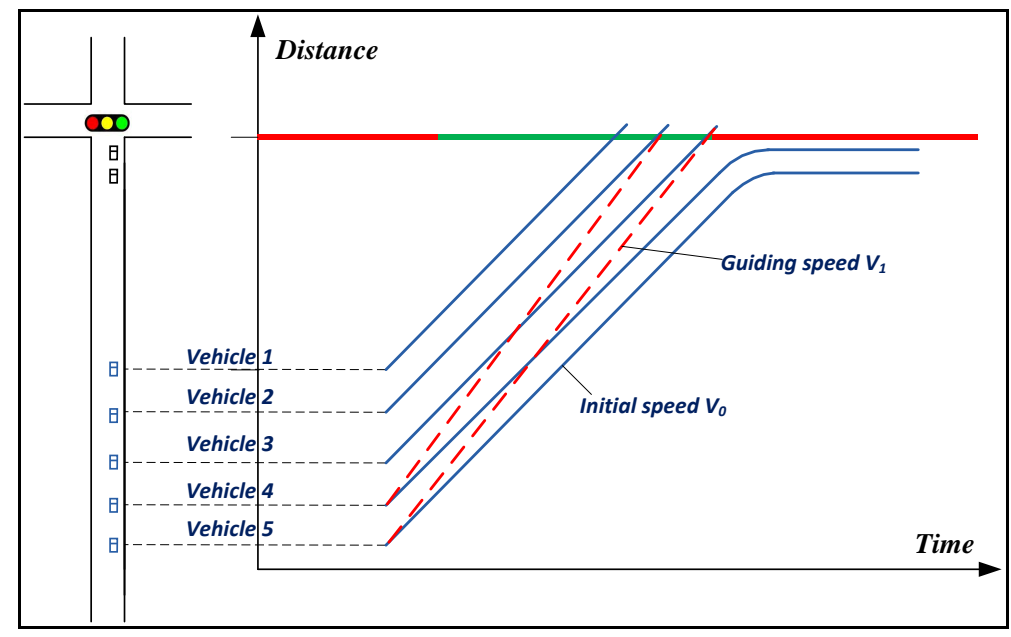

Figure 2: Speed guidance based on single-vehicle speed guidance method.

In Fig. 2, five vehicles named vehicle 1 to vehicle 5 need to be guided. For vehicle 1, vehicle 2 and vehicle 3 , cause they can clear the intersection normally with the initial speed $V_{0}$, therefore, according to the rules of "single-vehicle speed guidance method", speed guidance is not required for them. For vehicles 4 and 5, speed guidance is required; they need to accelerate from initial speed $V_{0}$ to guiding speed $V_{1}$ in order to clear the intersection. However, cause vehicle 1 , vehicles 2 and 3 travel with initial speed $V_{0}$ thus block the way vehicles 4 and 5 can proceed, vehicles 4 and 5 will experience extra delay and stops at the red light.

In Fig. 3, Speed guidance based on multi-vehicles cooperated speed guidance method is giving. Five vehicles accelerate to guiding speed $V_{1}$ and then all vehicles will clear the intersection without stopping.

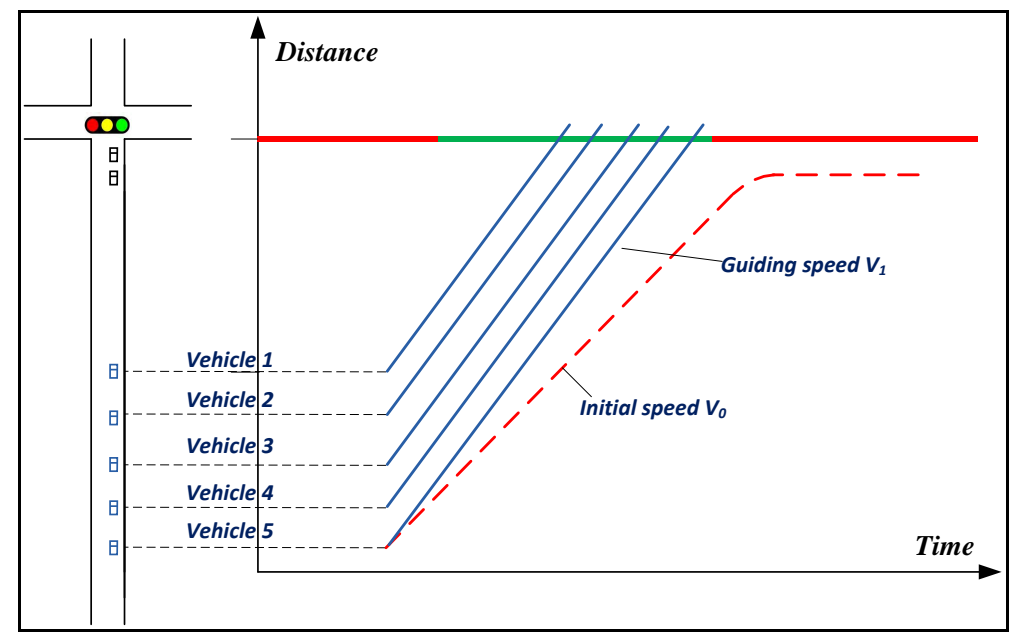

Figure 3: Speed guidance based on multi-vehicles cooperated speed guidance method.

The strategy of multi-vehicles cooperated speed guidance method is shown in Fig. 4. The green durations are divided into small pieces called "green piece" according to the minimal time headway $t_{s}$ between adjacent vehicles. Then green piece 1 will allocate to the first vehicle in the approach. Green piece 2 will allocate to the second vehicle in the approach, etc. If the vehicle is too far away from the stop line, and cannot arrive the intersection in allocated green piece. Then the subsequent green piece will be allocated to that vehicle. For example, if vehicle 1 cannot arrive in green piece 1 , then green piece 2 will be allocated to it, if green piece 2 does not work also, then green piece 3 will be considered and so on. 


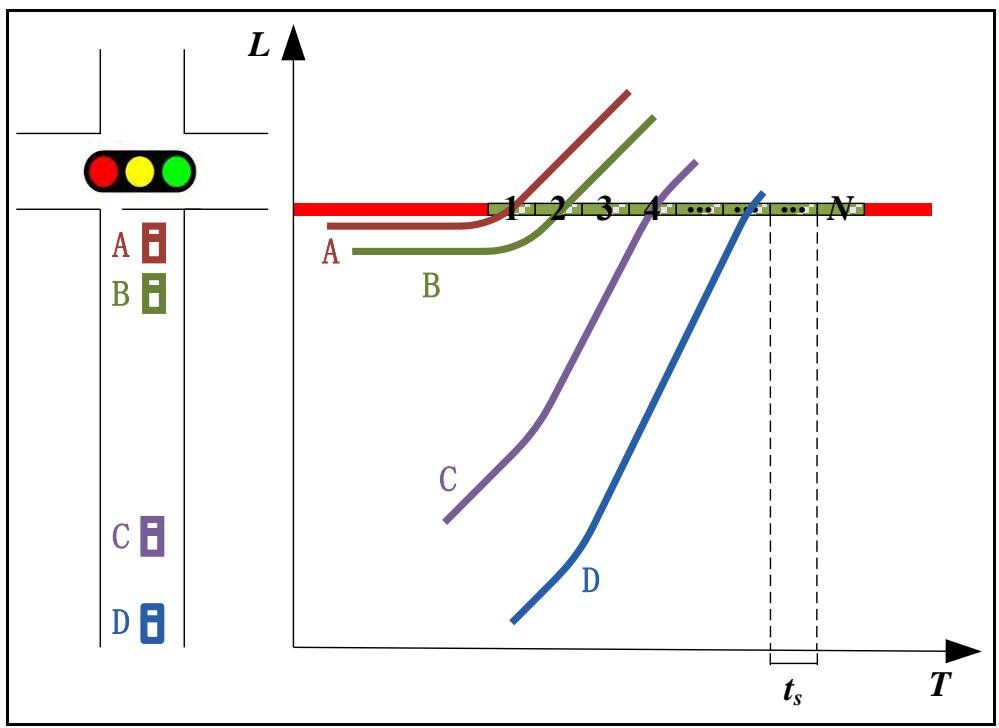

Figure 4: The strategy of multi-vehicles cooperated speed guidance method.

\subsection{Single-vehicle speed guidance method}

Single-vehicle speed guidance method contains two different cases.

Case 1: when vehicles arrive, traffic light is red, or traffic light is green but queues in front of the stop line are still not dissipated.

Case 2: when vehicles arrive, traffic light is green and queues in front of the stop line are dissipated.

For case 1, the objective of the speed guidance is to minimize the stop delay. The best solution is the vehicle reaches the queue tail when the last car begins moving, as can be shown in Fig. 5. And the objective function can be specified as:

$$
\min \left(T_{d}-T_{a}\right)
$$

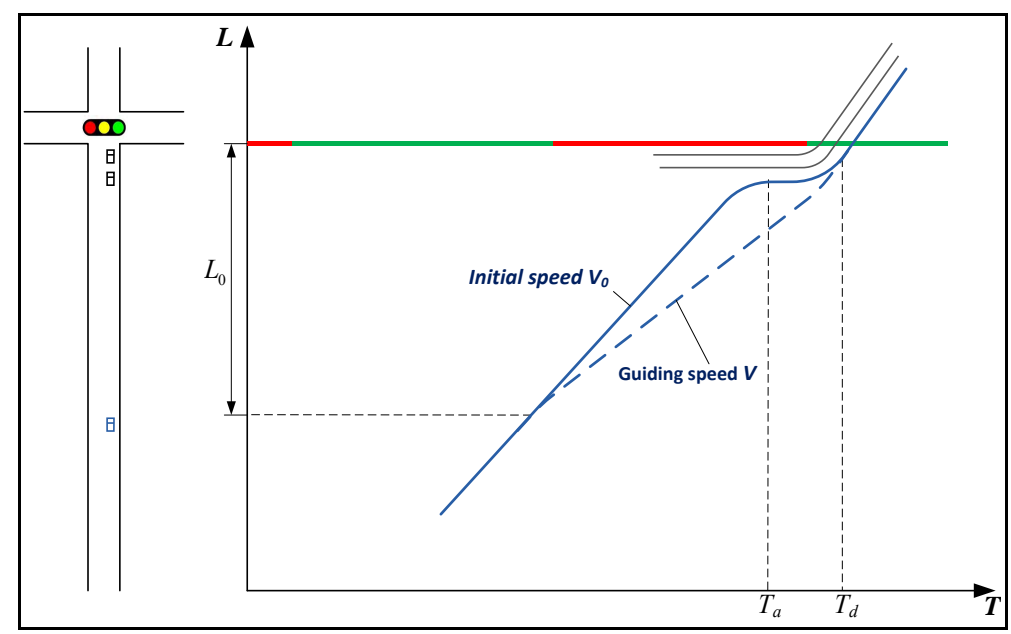

Figure 5: Vehicle speed guidance of cases 1 and 2.

In case 2, the objective of the speed guidance is to make the vehicle clear the intersection before the end of the green light. As can be shown in Fig. 6, the objective function can be specified as:

$$
\min \left(T_{a}-T_{g}^{e}\right)
$$




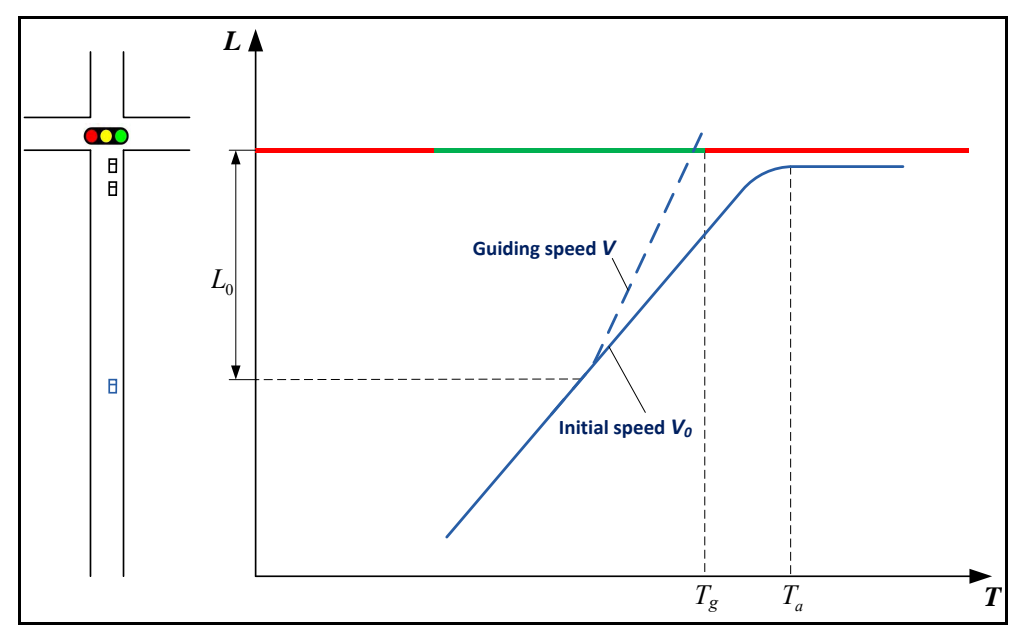

Figure 6: Vehicle speed guidance of case 2.

\subsection{Multi-vehicles cooperated speed guidance method}

\section{(1) Objective function}

There are two steps for a vehicle to accept speed guidance and then clear the intersection without stopping.

Step 1: Accelerate or decelerate to objective speed optimized by multi-vehicles cooperated speed guidance method.

Step 2: Travel with objective speed then clear the intersection.

The time for a vehicle passes the stop line can be compute as:

$$
T_{i}=T_{0}+\left|\frac{V_{i}-V_{i 0}}{a}\right|+\frac{L_{i}-\left|\frac{V_{i}^{2}-V_{i 0}^{2}}{2 a}\right|}{V_{i}}
$$

If $V_{i 0} \geq V_{i}$, then the objective speed $V_{i}$ can be computed as:

$$
V_{i}=V_{i 0}-a t_{i}+\sqrt{a^{2} t_{i}^{2}-2 a t_{i} V_{i 0}+2 a L_{i}}
$$

If $V_{i 0}<V_{i}, V_{i}$ can be computed as:

$$
V_{i}=V_{i 0}+a t_{i}-\sqrt{a^{2} t_{i}^{2}+2 a t_{i} V_{i 0}-2 a L_{i}}
$$

where:

$$
t_{i}=T_{i}-T_{0}
$$

The delay for a vehicle can be compute as:

$$
D_{i}=t_{i}-\frac{L_{i}}{V_{f}}
$$

Then the objective of multi-vehicles cooperated speed guidance method can be specified as:

$$
\min \sum_{i=1}^{N} D_{i} / N
$$

\section{(2) Constrains}

The time for the first vehicle passes through the intersection should be greater than the time that green light begins, as shown in eq. (9):

$$
T_{1} \geq T_{g}
$$


The time headways between vehicles should be greater than the minimum time headway:

$$
T_{i} \geq T_{i-1}+t_{s}
$$

For all the vehicles that can clear the intersections in current cycle, the time that vehicles clear the intersection should be smaller than the end time of the green light:

$$
T_{g}+t_{g} \geq T_{i}
$$

The total number of vehicles that can travel through the intersection $(N)$ can be set as:

$$
N \leq \frac{S * l * g_{e}}{3600}
$$

The objective speed after speed guidance can be set as:

$$
V_{\min } \leq V_{i} \leq V_{\max }
$$

\section{SIMULATION MODELING}

\subsection{Basic parameters}

This study employs an example intersection to illustrate the applicability of the proposed speed guidance method. This intersection located in Shanghai, China, named Cao'an RoadLvyuan Road intersection. For safety reasons, field test is not allowed. Therefore, with the assistance of VISSIM platform, a simulation model has been formulated. The basic layout of the study area is shown in Fig. 7.

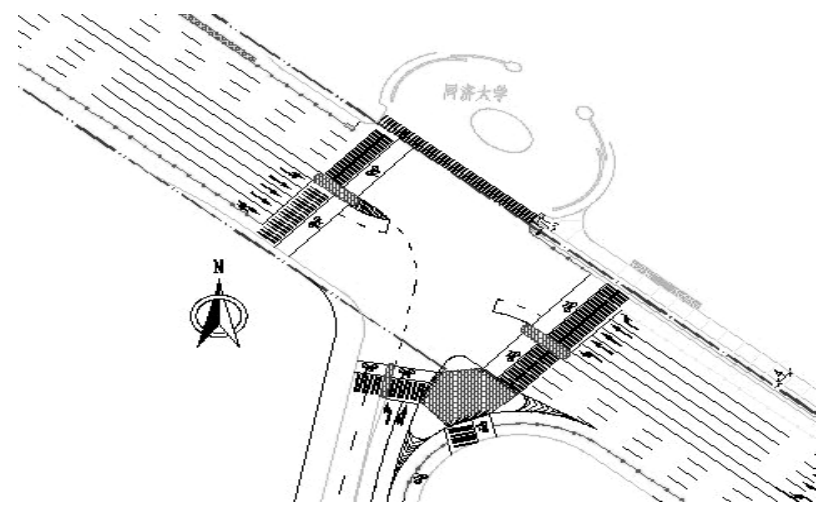

a) Field intersection

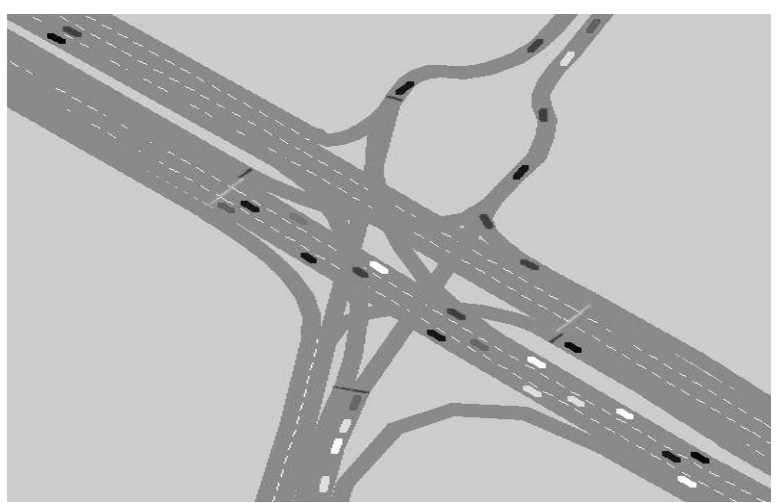

b) Intersection in a simulation model

Figure 7: Basic layout of the study area.

Tables II and III summarize all experimental parameters. Every single simulation period is defined to be one hour. Performance data (delay, number of stops) are collected for each simulation run.

Table II: Lane distribution of study area.

\begin{tabular}{|c|c|c|c|c|c|c|c|c|c|c|}
\hline Directions & \multicolumn{3}{|c|}{ Westbound } & \multicolumn{3}{c|}{ Eastbound } & \multicolumn{3}{c|}{ Northbound } & Southbound \\
\hline $\begin{array}{c}\text { Lane } \\
\text { distribution }\end{array}$ & $\begin{array}{c}\text { Left } \\
\text { turn }\end{array}$ & Through & $\begin{array}{c}\text { Right } \\
\text { turn }\end{array}$ & $\begin{array}{c}\text { Left } \\
\text { turn }\end{array}$ & Through & $\begin{array}{c}\text { Right } \\
\text { turn }\end{array}$ & $\begin{array}{c}\text { Left } \\
\text { turn }\end{array}$ & Through & $\begin{array}{c}\text { Right } \\
\text { turn }\end{array}$ & $\begin{array}{c}\text { Multifunctional } \\
\text { lane }\end{array}$ \\
\hline $\begin{array}{c}\text { Number of } \\
\text { lanes }\end{array}$ & 1 & 3 & 1 & 1 & 3 & 1 & 1 & 1 & 1 & 1 \\
\hline
\end{tabular}


Table III: Parameters of signal controller.

\begin{tabular}{|l|c|c|c|c|}
\hline Signal Phases & \multicolumn{2}{|c|}{ 1 } & \multicolumn{2}{c|}{ 2 } \\
\hline Directions & Westbound & Eastbound & Northbound & Southbound \\
\hline Phase Time & \multicolumn{2}{|c|}{37} & \multicolumn{2}{|c|}{27} \\
\hline Yellow and All-Red & \multicolumn{2}{|c|}{3} & \multicolumn{2}{|c|}{} \\
\hline Cycle Time & \multicolumn{2}{|c|}{70} \\
\hline
\end{tabular}

\subsection{Simulation modelling}

Speed guidance can be realized by means of VISSIM platform, Visual Basic platform and VISSIM-COM (Component Object Model) interface. The flowcharts of the simulation and optimization methods are shown in Figs. 8 and 9. Sliding time window is adopted to dynamically optimize the problems.

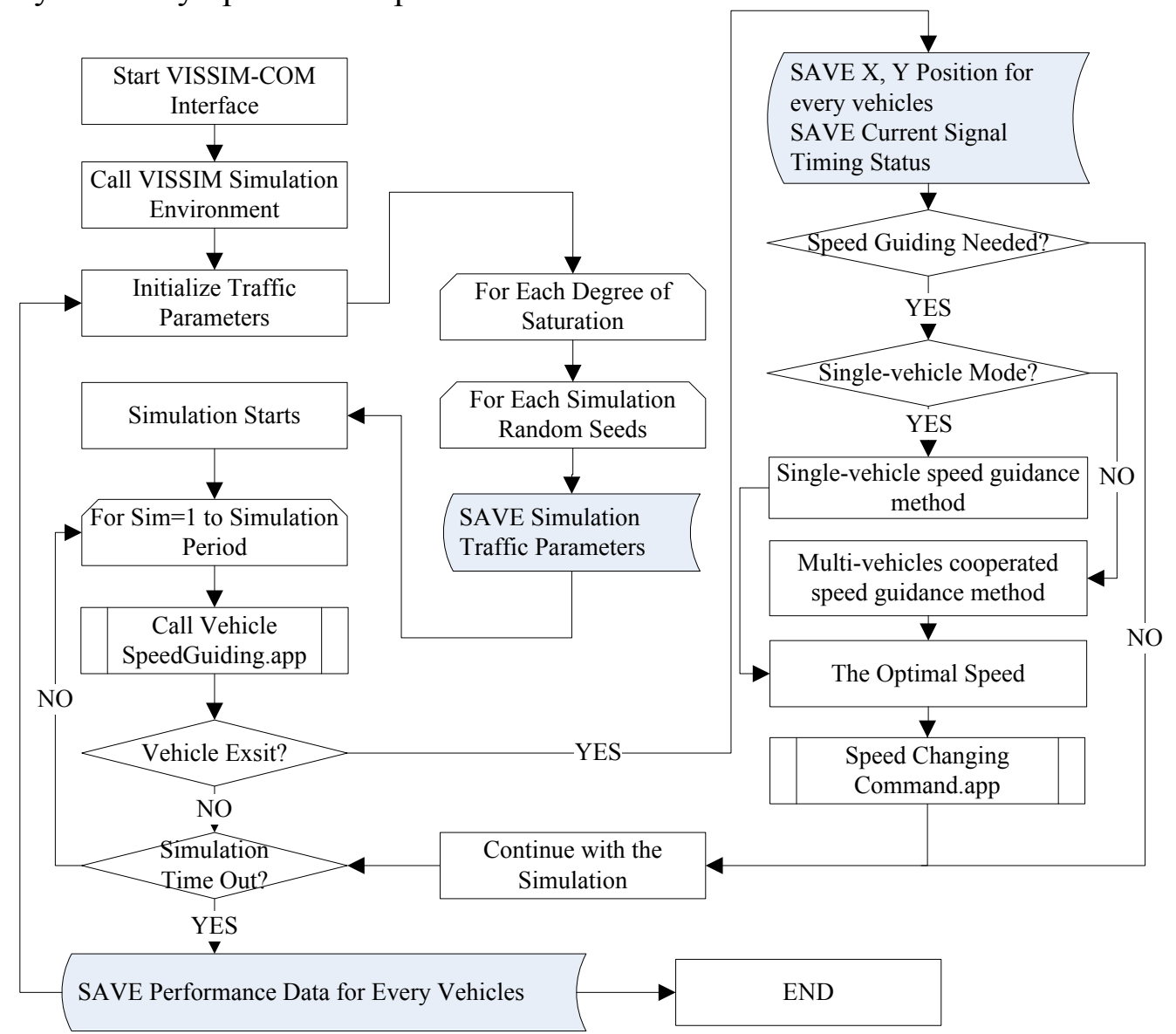

Figure 8: Flowchart of the simulation process.

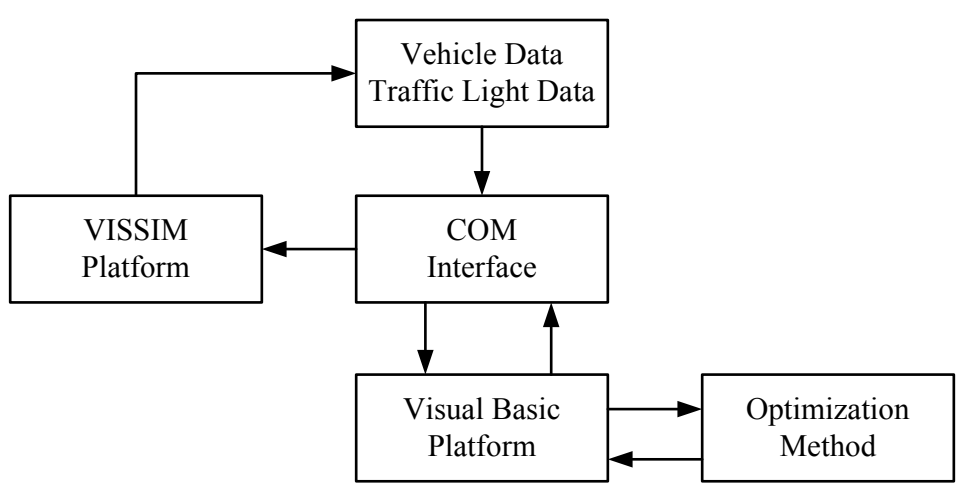

Figure 9: Simulation structure. 


\subsection{Simulation calibration}

Particle swarm optimization (PSO) has been employed to calibrate the simulation parameters. In this paper, simulation parameters need to be calibrated are as follow:

$a x$ : The standstill distance;

$b x \_a d d$ : Additive part of desired safety distance;

$b x \_$mult: Multiplicative part of desired safety distance;

$N_{l}$ : Observed vehicles ahead;

$d_{1}$ : Emergency stopping distance;

$d_{2}$ : Distance for vehicles change lanes.

After optimization, the solutions are shown in Table IV.

Table IV: Optimized parameter solution based on PSO.

\begin{tabular}{|l|c|c|c|c|c|c|}
\hline Parameters & $a x$ & $b x \_a d d$ & $b x \_$mult & $N_{1}$ & $d_{1}$ & $d_{2}$ \\
\hline Optimal results & 2.34 & 3.54 & 4.76 & 1 & 5.5 & 195.3 \\
\hline
\end{tabular}

\section{PERFORMANCE ANALYSIS}

To evaluate the performance of the proposed strategies, the degree of saturation (volume-tocapacity ratio) is varied from 0.1 to 0.9 , three cases are compared:

1) Case 1: no speed guidance;

2) Case 2: single-vehicle speed guidance method; and

3) Case 3: multi-vehicles cooperated speed guidance method.

Fig. 10 shows the comparison of number of stops for each of the above cases.

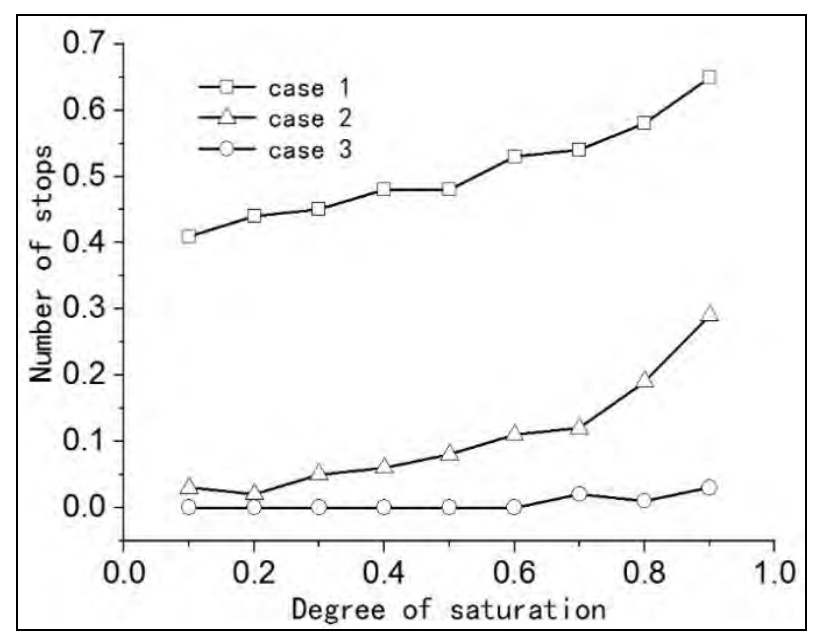

Figure 10: Comparison of number of stops for different cases.

As indicated in Fig. 10, the number of stops of case 1 and case 2 increases with the increase of degree of saturation. Compared with case 1, by the means of speed guidance, case 2 can decrease number of stops by $70.3 \%$. Especially when the degree of saturation is low, the number of stops in case 2 approaches zero. With respect to case 3 , with the increase of degree of saturation, the number of stops remains relatively stable and outperforms cases 1 and 2. Fig. 11 shows the comparison of average delay for each of the above cases. 


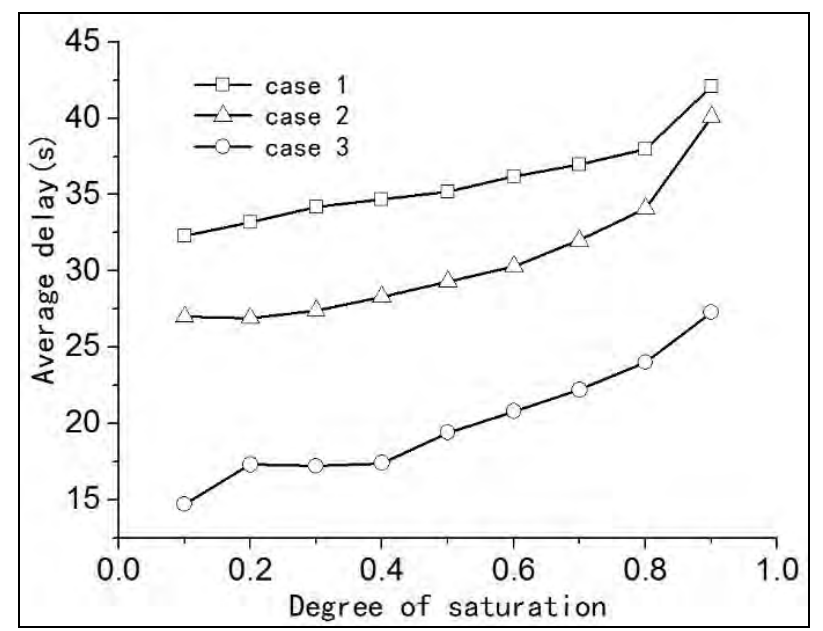

Figure 11 Comparison of average delay for different cases.

In Fig. 11, the average delay of all cases increases with the increase of degree of saturation. Case 2 can decrease average delay by $15.6 \%$ compared with case 1 . Case 3 outperforms cases 1 and case 2 with decreases in average delay of $51.2 \%$ and $25.9 \%$ respectively. Compared with case 2, case 3 can decrease average delay more effectively. When degree of saturation is great than 0.8 , the benefits of speed guidance for case 2 is small.
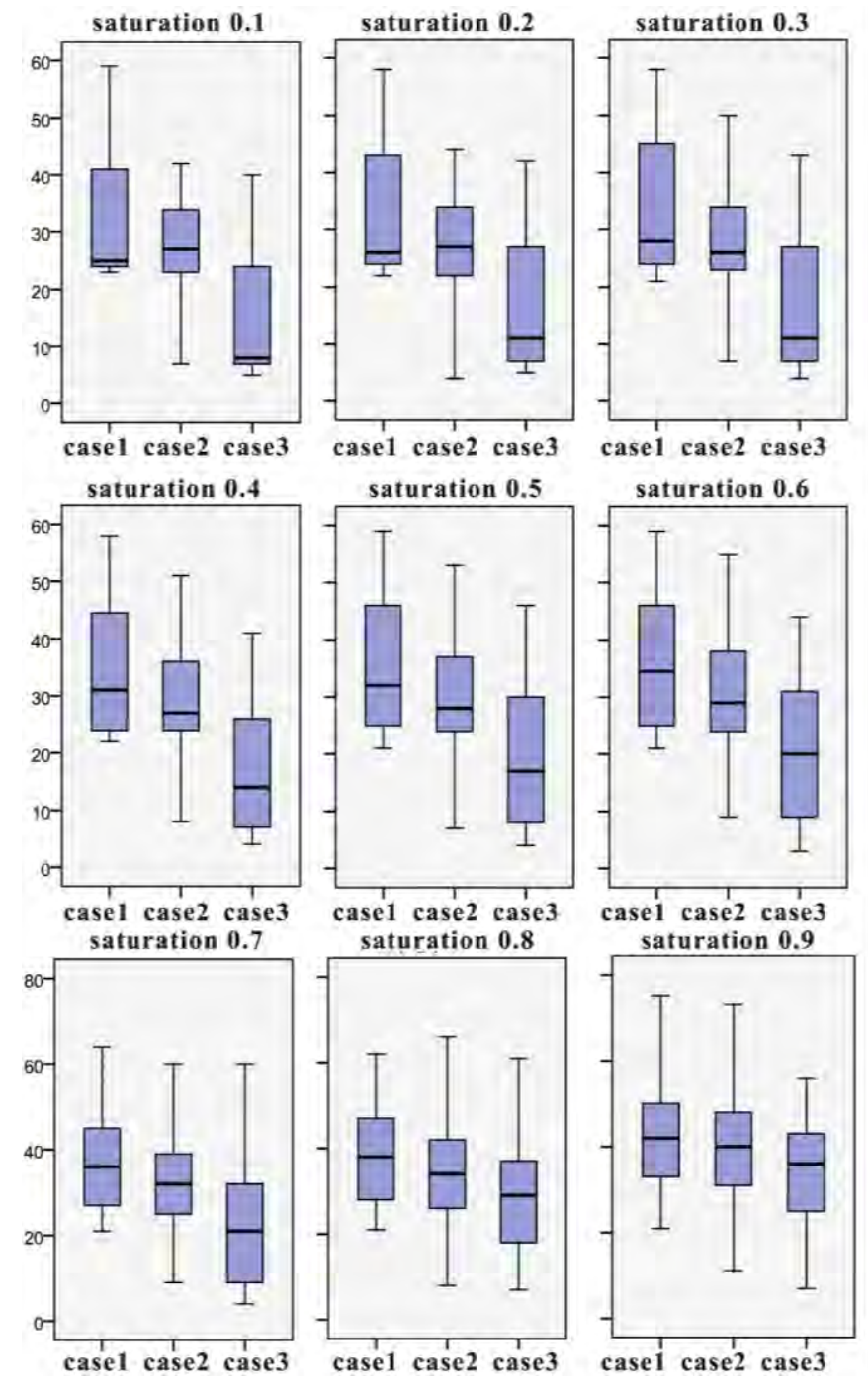

Figure 12: Comparison of average delay with box plot. 
Compared with case 1 , the main reason case 2 can decrease the average delay is that the peak value of the average delay in case 2 is decreased by single vehicle speed guidance (Fig. 11). But the main part of the average delay (Fig. 12) remains about the same. This illustrates that single vehicle speed guidance strategy makes no difference for most of vehicles. But in case 3, based on multi-vehicles cooperated speed guidance method, the main part of the average delay decreases significantly, this testify that multi-vehicles cooperated speed guidance method can serve more vehicles, decrease overall delays in various situations.

\section{CONCLUSIONS}

Based on the two way communication between vehicles and signal controller in Connected Vehicle (CV) environment, vehicle travel speed can be dynamically adjusted according to the current signal status and traffic conditions. This paper presented a novel approach for the optimization of travel speeds to provide priority to vehicles at isolated intersections. The objective of the proposed method was to minimize the average delay, ensuring that the vehicles clear the intersection without stopping at a red light. Two different types of vehicle speed guidance methods including "single-vehicle speed guidance model" and "multi-vehicles cooperated speed guidance model" are proposed. VISSIM platform, Visual Basic and VISSIM-COM interface are employed to build the simulation model. Simulation analyses indicated that speed guidance can significantly decrease average delay as well as number of stops. "Single-vehicle speed guidance method" can decreased the average delay by $15.6 \%$ and average number of stops by $70.3 \%$ compared with "no speed guidance method". "Multivehicles cooperated speed guidance method" decreased the average delay by $51.2 \%$ and $25.9 \%$ compared with "Single-vehicle speed guidance method" and "no speed guidance method", respectively. The number of stops of "Multi-vehicles cooperated speed guidance method" approaches zero despite the fluctuation of degree of saturation. Further analyses with box plot were also proved "multi-vehicles cooperated speed guidance method" can serve more vehicles, decrease overall delays in various situations.

This paper presented preliminary simulation analysis and results for the proposed method for an isolated intersection. More extensive simulation experiments or field tests will be conducted in the future to assess the effectiveness of the proposed model under various traffic and demand patterns, signal timing strategies (e.g., adaptive signal control), and Connected Vehicle (CV) penetration. Corridor-wide or system-wide evaluation of the proposed model's performance should also be conducted in future studies.

\section{ACKNOWLEDGMENT}

The research is supported by the National Natural Science Foundation of China under Grant No. 51308336 and No. 51408065, the National Social Science Foundation of China under Grant No. 14BSH032, the Natural Science Foundation of Hunan Province under Grant No. 2015JJ6001, and the Research Foundation of Education Bureau of Hunan Province under Grant No. 14B003.

\section{REFERENCES}

[1] Zhang, Y.; Li, Y.; Liu, Q. X.; Li, C. Y. (2014). The built environment and walking activity of the elderly: An empirical analysis in the Zhongshan Metropolitan Area, China, Sustainability, Vol. 6, No. 2, 1076-1092, doi: $10.3390 / \mathrm{su} 6021076$

[2] Zhang, Y.; Li, Y.; Yang, X.; Liu, Q. X.; Li, C. Y. (2013). Built environment and household electric bike ownership, Transportation Research Record: Journal of the Transportation Research Board, Vol. 2387, No. 1, 102-111, doi:10.3141/2387-12 
[3] Zhang, Y.; Yang, X. G.; Li, Y.; Liu, Q. X.; Li, C. Y. (2014). Household, personal and environmental correlates of rural elderly's cycling activity: Evidence from Zhongshan Metropolitan Area, China, Sustainability, Vol. 6, No. 6, 3599-3614, doi:10.3390/su6063599

[4] Zhang, Y.; Wu, W.; Li, Y.; Liu, Q. X.; Li, C. Y. (2014). Does the built environment make a difference? An investigation of household vehicle use in Zhongshan Metropolitan Area, China, Sustainability, Vol. 6, No. 8, 4910-4930, doi:10.3390/su6084910

[5] Sprague, D. (2012). Adaptive signal timing: comparison between the Insync and QuicTrac adaptive signal systems installed in Colorado, Research Report 2012-6, Dept. of Transportation, from http://www.coloradodot.info/programs/research/pdfs/2012/adaptivesignaltiming.pdf/view, accessed on 17-12-2013

[6] Li, J.-Q.; Wu, G.; Zou, N. (2011). Investigation of the impacts of signal timing on vehicle emissions at an isolated intersection, Transportation Research Part D: Transport and Environment, Vol. 16, No. 5, 409-414, doi:10.1016/j.trd.2011.03.004

[7] Zhang, L.; Yin, Y.; Lou, Y. (2010). Robust signal timing for arterials under day-to-day demand variations, Transportation Research Record: Journal of the Transportation Research Board, Vol. 2192, No. 1, 156-166, doi:10.3141/2192-15

[8] Webster, F. V. (1958). Traffic Signal Settings, Great Britain Road Research Laboratory, London

[9] Liu, Y.; Chang, G.-L. (2011). An arterial signal optimization model for intersections experiencing queue spillback and lane blockage, Transportation Research Part C: Emerging Technologies, Vol. 19, No. 1, 130-144, doi:10.1016/j.trc.2010.04.005

[10] Little, J. D.; Kelson, M. D.; Gartner, N. H. (1981). Maxband: A Versatile Program for Setting Signals on Arteries and Triangular Networks, Alfred P. Sloan School of Management of Massachusetts Institute of Technology, Cambridge

[11] Wong, C. K.; Wong, S. C. (2003). A lane-based optimization method for minimizing delay at isolated signal-controlled junctions, Journal of Mathematical Modelling and Algorithms, Vol. 2, No. 4, 379-406, doi:10.1023/B:JMMA.0000020424.32940.cb

[12] Gartner, N. H.; Pooran, F. J.; Andrews, C. M. (2001). Implementation of the OPAC adaptive control strategy in a traffic signal network, IEEE Proceedings on Intelligent Transportation Systems, 195-200

[13] Robertson, D. I. (1969). Transyt: A Traffic Network Study Tool, Road Research Laboratory, Crowthorne

[14] Head, K. L.; Mirchandanai, P. B.; Shelby, S. (1998). The Rhodes Prototype: A Description and Some Results, Transportation Research Board, Washington, D.C.

[15] Yu, X.-H.; Recker, W. W. (2006). Stochastic adaptive control model for traffic signal systems, Transportation Research Part C: Emerging Technologies, Vol. 14, No. 4, 263-282, doi:10.1016/ j.trc.2006.08.002

[16] Wong, C.; Wong, S.; Lo, H. K. (2010). A spatial queuing approach to optimize coordinated signal settings to obviate gridlock in adjacent work zones, Journal of Advanced Transportation, Vol. 44, No. 4, 231-244, doi:10.1002/atr.123

[17] Xuan, Y.; Daganzo, C. F.; Cassidy, M. J. (2011). Increasing the capacity of signalized intersections with separate left turn phases, Transportation Research Part B: Methodological, Vol. 45, No. 5, 769-781, doi:10.1016/j.trb.2011.02.009

[18] Skabardonis, A.; Geroliminis, N. (2008). Real-time monitoring and control on signalized arterials, Journal of Intelligent Transportation Systems: Technology, Planning, and Operations, Vol. 12, No. 2, 64-74, doi:10.1080/15472450802023337

[19] Liu, Y.; Chang, G.-L.; Yu, J. (2011). An integrated control model for freeway corridor under nonrecurrent congestion, IEEE Transactions on Vehicular Technology, Vol. 60, No. 4, 14041408, doi:10.1109/TVT.2011.2115264

[20] Choi, J.; Tay, R.; Kim, S. (2013). Effects of changing highway design speed, Journal of Advanced Transportation, Vol. 47, No. 2, 239-246, doi:10.1002/atr.171

[21] Abu-Lebdeh, G. (2010). Exploring the potential benefits of IntelliDrive-enabled dynamic speed control in signalized networks, Proceedings of the $89^{\text {th }}$ Annual Meeting of the Transportation Research Board, Paper 10-3031, 20 pages 
[22] Daganzo, C. F.; Pilachowski, J. (2011). Reducing bunching with bus-to-bus cooperation, Transportation Research Part B: Methodological, Vol. 45, No. 1, 267-277, doi:10.1016/ j.trb.2010.06.005

[23] Liu, Y.; Dion, F.; Biswas, S. (2005). Dedicated short-range wireless communications for intelligent transportation system applications: State of the art, Transportation Research Record: Journal of the Transportation Research Board, Vol. 1910, No. 1, 29-37, doi:10.3141/1910-04

[24] He, Q.; Head, K. L. (2010). Lane-Level Vehicle Positioning with Low-Cost GPS, Proceedings of the $89^{\text {th }}$ Annual Meeting of the Transportation Research Board, Paper 10-2458, 15 pages

[25] He, Q.; Head, K. L.; Ding, J. (2012). PAMSCOD: Platoon-based arterial multi-modal signal control with online data, Transportation Research Part C: Emerging Technologies, Vol. 20, No. 1, 164-184, doi:10.1016/j.trc.2011.05.007

[26] Ding, J.; He, Q.; Head, L.; Saleem, F.; Wu, W. (2013). Development and testing of priority control system in connected vehicle environment, Proceedings of the $92^{\text {th }}$ Annual Meeting of the Transportation Research Board, Paper 13-3025, 19 pages

[27] Head, L.; Shladover, S.; Siripurapu, R.; McNew, J.; Duncan, G.; Kelley, D.; Siebert, M. (2013). Multi-modal intelligent traffic signal system: Development of concept of operations, system requirements, system design and a test plan, from https://www.transportationresearch.gov/ dotrc/cv/Lists/Researches/Attachments/12/PFS_MMITSS01_Summary.pdf, accessed on 21-102013

[28] Andrews, S.; Cops, M. (2009). Vehicle Infrastructure Integration: Integration Proof of Concept Technical Description - Vehicle, U.S. Department of Transportation, Washington, D.C. 